\title{
Oral Sulfate Solution versus Polyethylene Glycol as a Single-Day Preparation for Colonoscopy: A Randomized Control Trial
}

\author{
Bhavik Bharat Shah ${ }^{1}$ Bubun Patel ${ }^{1}$ Mahesh Kumar Goenka \\ ${ }^{1}$ Institute of Gastrosciences and Liver, Apollo Gleneagles Hospitals, \\ Address for correspondence Dr. Mahesh Kumar Goenka, Institute of \\ Kolkata, West Bengal, India \\ Gastrosciences and Liver, Apollo Gleneagles Hospitals, Kolkata, West \\ Bengal, India (e-mail: gastrojournal_aghl@apollohospitals.com).
}

J Digest Endosc 2019;10:174-177

\begin{abstract}
Keywords

- colonoscopy preparation

- oral sulfate solution

- polyethylene glycol

Background Colonoscopy is a principal diagnostic tool for most colonic disorders. Adequate bowel preparation is essential for proper visualization of the mucosa. The aim of this study was to compare the tolerability, efficacy, and safety profile of $1 \mathrm{~L}$ of oral sulfate solution (OSS) in comparison to $2 \mathrm{~L}$ of polyethylene glycol (PEG) solution.

Methods In this single-center prospective study conducted at our institute, patients were randomly assigned to receive either OSS or PEG solutions for colonoscopy preparation. Patients enrolled in either group completed a questionnaire assessing the taste of the solution used, adverse effects, and number of stools passed. Grading of the bowel cleansing quality was done as per Boston Bowel Preparation (BBP) score.

Results Total of 400 patients, with 222 patients in the PEG group and 178 patients in the OSS group, were assessed. In the PEG group, 148 (66.75\%) patients were males and in the OSS group 112 (62.9\%) patients were males. There was no statistical significance on comparison of the taste as "good" or "bad" in both groups. All the adverse events were mild to moderate in intensity and their frequencies were comparable for both the groups. The OSS group had better bowel preparation as per the BBP score $(p=0.021)$ and lesser cecal intubation time $(p=0.028)$.

Conclusion The present study demonstrated that $1 \mathrm{~L}$ of OSS is better than the well-established 2 L PEG solution, in terms of bowel preparation and shorter time to cecal intubation.
\end{abstract}

\section{Introduction}

Colonoscopy is performed as a principal diagnostic tool in most colonic disorders. Adequate bowel preparation is essential for proper visualization of the colonic mucosa. Superior cleansing minimizes the risk of missing lesions, need for repeat procedure and associated increase in cost of colonoscopy, improves cecal intubation, and decreases patient's discomfort. ${ }^{1,2}$

Per oral polyethylene glycol (PEG) solution has been the most commonly used cleansing agent in recent years. This is a nondigestible, nonabsorbable, osmotically balanced laxative lavage solution, that does not alter fluid and electrolyte balance. ${ }^{3-6}$ The oral sulfate solution (OSS) has been a recently developed formulation which can be administered as a sameday regimen for bowel preparation. In earlier studies, OSS has shown not to alter the serum electrolyte balance and also urine from study subjects did not commonly form a calcium precipitate. ${ }^{7.8}$ Unlike sodium phosphate, high doses of OSS administered to rats and dogs showed no evidence of soft tissue or kidney calcification. ${ }^{9}$ However, the major benefit of OSS is that only $1 \mathrm{~L}$ of solution has to be consumed, as compared with 2 L of PEG solution. This may increase patient's comfort. The purpose of this study was to compare the tolerability, efficacy, and safety profile of OSS in comparison to PEG solution. 


\section{Patients and Methods}

This was a randomized, double-blinded, single-center study conducted at our institute from July 2018 to February 2019. Patients aged more than 18 years, from the outpatient and inpatients department, who were scheduled to undergo colonoscopy were enrolled. A written informed consent was obtained from each patient. Patients with $>50 \%$ colon resection, severe constipation ( $<1$ bowel movement per week), known or suspected gastroparesis, severe nausea or vomiting, bowel obstruction, cardiac and renal failure, pregnancy, and lactation were excluded. The eligible patients were randomly assigned by the envelope method to OSS and PEG groups by endoscopy room staff not involved in the colonoscopy procedure.

All study procedures were performed by trained gastroenterologists. Patients in the PEG group were asked to consume $137.15 \mathrm{~g}$ of commercially available PEG powder with electrolytes in $2 \mathrm{~L}$ of water to prepare a solution. In the OSS group, $117 \mathrm{~mL}$ of OSS was mixed with cold or normal water as required to make a total solution of $500 \mathrm{~mL}$. Two such bottles were given to the patient, each of which had to be consumed over 10 to 20 minutes, keeping a gap of 1 hour in between the two. Preparations in both the groups were initiated 6 to 8 hours before the colonoscopy.

All the enrolled patients completed a questionnaire assessing the taste of the solution, adverse effects, and number of stools passed for either group. Adverse effects, like nausea, vomiting, abdominal pain, headache, fatigability, and others, were scored on a 5 -point scale, where 1 = "none"; 2 = "mild"; 3 = "bothersome"; 4 = "distressing"; and 5 = "severely distressing." This scale has been used in earlier bowel cleansing studies. ${ }^{7}$ Total time taken to complete the procedure, cecal intubation and extubation time, was noted by the endoscopist performing the procedure. Grading of the preparation quality was done as per the Boston Bowel Preparation (BBP) score, which has excellent interobserver reliability, and is proven to be related to the endoscopy outcome. ${ }^{10,11}$ Total BBP score $^{3}$ of 6 was taken as adequate preparation and score of $<6$ was considered inadequate preparation. ${ }^{12-14}$

\section{Statistical Analysis}

Statistical Analysis was performed with the help of Epi Info 3.5.3. Epi Info is a trademark of the Centers for Disease Control and Prevention. Descriptive statistical analysis was performed to prepare the tables. Comparison between the groups was done with Mann-Whitney, chi-square, and $t$-test as needed. Statistical difference was considered significant when $p$-value was $<0.05$.

\section{Results}

During the study period, 400 outpatients were evaluated, out of which 222 (55.5\%) patients received PEG preparation and 178 (44.5\%) received OSS preparation. In the PEG group 148 (66.75\%) patients were males and in the OSS group 112 (62.9\%) patients were males. The mean ( \pm standard deviation) age of patients in the PEG group was $43.87( \pm 13.52)$ years and in the OSS group was $43.89( \pm 13.67)$ years $(p=0.91)$. - Table 1 shows various indications for which colonoscopy was performed in both the groups. Clinically suspected irritable bowel syndrome and constipation were the most common indication in both the groups. When the taste sensation was compared on the basis of questionnaire, "good taste" was observed in 134 (60.4\%) patients in the PEG group and 101 (56.7\%) patients in the OSS group. The comparison between the two groups was not statistically significant $(p=0.57)$. Similarly, the rest of the patients observed "bad taste" which was also not statistically significant $(p=0.57)$ between the two groups. The colonoscopy findings were comparable in the PEG and OSS groups (- Table 2).

In both the groups, the most common complaint after consumption of PEG and OSS was nausea, vomiting, and abdominal bloating. The frequencies of reported adverse events, including nausea, vomiting, abdominal pain, abdominal bloating, headache, fatigue, and reeling to the head, were comparable in both the groups (-Table $\mathbf{3}$ ). All the adverse events were mild to moderate in intensity. No serious adverse events occurred in both the groups.

Complete examination of the colon was possible in 390 (97.5\%) patients. Ten patients required repeat preparation. There was no difference in the two groups for the requirement of repeat preparation ( $2.7 \%$ vs. $2.2 \%, p=0.88)$. For assessment of cleanliness, quality was assessed in 390 patients in whom complete colonoscopy could be achieved. The significant difference ( $p=0.021$ ) was seen favoring the OSS group in bowel cleansing as per the BBP score ( - Table 4 ). The time required for cecal intubation was $5.23 \pm 3.35 \mathrm{~min}$ utes in the OSS group as compared with $6.05 \pm 4.1$ minutes in the PEG group, which was significantly less $(p=0.028)$. We also found that as the number of stools passed after consumption of either preparation were higher than 6 , BBP score also improved $(p=0.001)$.

Table 1 Indications of colonoscopy in the two groups

\begin{tabular}{|l|l|l|}
\hline Indication & PEG $(\boldsymbol{n}=\mathbf{2 2 2})$ & OSS $(\boldsymbol{n}=178)$ \\
\hline Irritable bowel syndrome & $70(31.5)$ & $74(41.5)$ \\
\hline Inflammatory bowel disease & $12(5.4)$ & $11(6.2)$ \\
\hline Pain abdomen & $19(8.5)$ & $10(5.6)$ \\
\hline Gastrointestinal bleed & $25(11.3)$ & $14(7.1)$ \\
\hline Constipation & $61(27.5)$ & $47(26.4)$ \\
\hline Diarrhea & $13(5.9)$ & $9(5)$ \\
\hline Anemia & $6(2.7)$ & $3(1.7)$ \\
\hline Significant weight loss & $2(0.9)$ & $2(1.2)$ \\
\hline Colorectal cancer screening & $3(1.3)$ & $2(1.2)$ \\
\hline $\begin{array}{l}\text { Suspected partial intestinal } \\
\text { obstruction }\end{array}$ & $1(0.5)$ & 0 \\
\hline Fissure in ano & $2(0.9)$ & $1(0.6)$ \\
\hline Ileocecal ulcer & $5(2.2)$ & $2(1.2)$ \\
\hline Polypectomy & $2(0.9$ & 0 \\
\hline Abdominal Koch's & $1(0.5)$ & $3(1.7)$ \\
\hline
\end{tabular}

Abbreviations: OSS, oral sulfate solution; PEG, polyethylene glycol. Note: The indications were comparable in both groups $(p>0.05)$. 
Table 2 Colonoscopy findings in both groups, $\mathrm{n}(\%)$

\begin{tabular}{|l|l|l|}
\hline Colonoscopy findings & $\begin{array}{l}\text { PEG }(\boldsymbol{n}= \\
\mathbf{2 1 6})\end{array}$ & OSS $(\boldsymbol{n}=\mathbf{1 7 4})$ \\
\hline Normal & $127(58.8)$ & $108(62.1)$ \\
\hline Colonic polyp & $17(7.8)$ & $12(6.9)$ \\
\hline Hemorrhoids & $14(6.4)$ & $11(6.4)$ \\
\hline Ileal ulcer & $25(11.4)$ & $17(9.8)$ \\
\hline Fissure in ano & $4(1.8)$ & $2(1.1)$ \\
\hline Hemorrhoid + Fissure & $1(0.5)$ & $2(1.1)$ \\
\hline Inflammatory bowel disease & $5(2.3)$ & $3(1.7)$ \\
\hline Abdominal Koch's & $4(1.8)$ & $3(1.7)$ \\
\hline Diverticulosis & $4(1.8)$ & $3(1.7)$ \\
\hline Proctitis & $5(2.3)$ & $7(4)$ \\
\hline Worm infestation & $1(0.5)$ & 0 \\
\hline Colonic ulcer & $3(1.4)$ & $2(1.1)$ \\
\hline Ileocolonic ulcer & $4(1.8)$ & $2(1.1)$ \\
\hline Solitary rectal ulcer syndrome & $1(0.5)$ & 0 \\
\hline Carcinoma colon & 0 & $1(0.6)$ \\
\hline Telangiectasia & $2(0.9)$ & $1(0.6)$ \\
\hline
\end{tabular}

Abbreviations: OSS, oral sulfate solution; PEG, polyethylene glycol. Note: The colonoscopy findings were comparable in both groups $(p>0.05)$.

\section{Discussion}

The diagnostic accuracy of colonoscopy depends on the quality of bowel preparation. The adenoma detection rate is low if mucosal visualization is inadequate. ${ }^{15}$ Patient compliance and tolerability to the preparation agent is of utmost importance for a successful colonoscopy. The safety of the drug used for colonoscopy preparation is also an important consideration. There is an ongoing search for the ideal cleansing preparation, aiming at better patient compliance, shorter colonic preparation time, and better cleansing effects. Consumption of PEG is often associated with poor patient tolerance. In this study, we compared new OSS with PEG solution.

There were no differences in adverse effects with either preparation. Bowel cleansing quality was better in the OSS groups than in PEG. Cecal intubation was also significantly less in the OSS group. These combined with smaller volumes of ingestion with OSS preparation suggests OSS to be the preferred agent compared with PEG.

Di Palma et $\mathrm{al}^{7}$ in their study showed that patients receiving the entire OSS preparation in a day reported slightly increased gastrointestinal events and higher vomiting scores compared with 4-L PEG-electrolyte lavage solution (ELS). However, this was not seen in the split-dose regimen. Rex et $a{ }^{16}$ in a multicenter study of 136 patients receiving OSS

Table 3 Incidence of adverse events, $\mathrm{n}(\%)$

\begin{tabular}{|c|c|c|c|c|c|c|c|c|c|c|c|}
\hline \multirow[b]{2}{*}{$\begin{array}{l}\text { Symptom } \\
\text { scoring }\end{array}$} & \multicolumn{5}{|c|}{ PEG $(n=222)$} & \multicolumn{5}{|c|}{ OSS $(n=178)$} & \multirow[t]{2}{*}{$p$} \\
\hline & 1 & 2 & 3 & 4 & 5 & 1 & 2 & 3 & 4 & 5 & \\
\hline Nausea & $149(67.1)$ & $59(26.6)$ & $8(3.6)$ & $\begin{array}{l}6 \\
(2.7)\end{array}$ & 0 & $109(61.2)$ & $52(29.2)$ & $11(6.2)$ & $\begin{array}{l}6 \\
(3.4)\end{array}$ & 0 & 0.81 \\
\hline Vomiting & $209(94.2)$ & $8(3.6)$ & $2(0.9)$ & $\begin{array}{l}3 \\
(1.3)\end{array}$ & 0 & $161(90.5)$ & $12(6.7)$ & $4(2.2)$ & $\begin{array}{l}1 \\
(0.6)\end{array}$ & 0 & 0.89 \\
\hline Cramps & $213(96)$ & $9(4)$ & 0 & 0 & 0 & $170(95.5)$ & $3(1.7)$ & $3(1.7)$ & $\begin{array}{l}2 \\
(1.1)\end{array}$ & 0 & 0.88 \\
\hline Bloating & $189(85.1)$ & $32(14.4)$ & 0 & $\begin{array}{l}1 \\
(0.5)\end{array}$ & 0 & $155(87)$ & $20(11.2)$ & $2(1.2)$ & $\begin{array}{l}1 \\
(0.6)\end{array}$ & 0 & 0.84 \\
\hline Headache & 220 (99) & $1(0.5)$ & 0 & $\begin{array}{l}1 \\
(0.5)\end{array}$ & 0 & $177(99.4)$ & $1(0.6)$ & 0 & 0 & 0 & 0.89 \\
\hline Fatigue & $214(96.4)$ & $8(3.6)$ & 0 & 0 & 0 & $177(99.4)$ & 0 & $1(0.6)$ & 0 & 0 & 0.85 \\
\hline Other & $221(99.5)$ & 0 & $\begin{array}{l}1^{\mathrm{a}} \\
(0.5)\end{array}$ & 0 & 0 & $178(100)$ & 0 & 0 & 0 & 0 & 0.89 \\
\hline
\end{tabular}

Abbreviations: OSS, oral sulfate solution; PEG, polyethylene glycol.

Note: 1, None; 2, Mild; 3, Bothersome; 4, Distressing; 5, Severely distressing.

aReeling of the head.

Table 4 Preparation grade according to Boston Bowel Preparation (BBP) score, n (\%)

\begin{tabular}{|l|l|l|l|}
\hline Grade & PEG $(\boldsymbol{n}=220)$ & OSS $(\boldsymbol{n}=178)$ & $p$ \\
\hline Adequate $(\mathrm{BBP} \geq 6), n(\%)$ & $122(55.5)$ & $119(66.9)$ & $(0.021)$ \\
\cline { 1 - 3 } Inadequate $(\mathrm{BBP}<6), n(\%)$ & $98(44.5)$ & $59(33.1)$ & \\
\hline
\end{tabular}

Abbreviations: OSS, oral sulfate solution; PEG, polyethylene glycol. 
versus 4-L of SF-PEG-ELS showed, patients who ingested the OSS had less bloating, more successful preparation, and more frequent achievement of an excellent preparation (71.4\% vs. $34.3 \%, p=0.01$ ). Rex et $\mathrm{al}^{16}$ recently reported the results of a multicenter study that compared split-dose OSS with split-dose sodium picosulfate/magnesium citrate. Among 338 patients randomized to receive either preparation, OSS resulted in a higher rate of success (excellent or good) preparation (94.7\% vs. $85.7 \%$; $p=0.006$ ) and more excellent preparations ( $54 \%$ vs. $26 \%$; $p$ 0.001) compared with sodium picosulfate/magnesium citrate. Both preparations were well tolerated, and there was no difference in treatment emergent adverse events in both groups. Joshi et $\mathrm{al}^{17}$ in their cohort of 141 patients, compared PEG versus OSS preparation. Sulfate preparation resulted in better bowel cleansing $(p=0.01)$. Age, gender, and dosing schedule of preparation, including bedtime dosing of stimulant laxative, did not alter the BBP score. Nearly $15.4 \%$ of patients in their cohort reported side effects to these preparations. Our study has the limitations that we are not able to comment on "adenoma miss rate" due to study design. More study with a large number of patients may be required to validate our data.

The present study, however, demonstrated that 1 L OSS is better than well-established $2 \mathrm{~L}$ of PEG solution, in terms of bowel preparation and shorter time to cecal intubation with similar adverse events. More studies with a larger number of patients may be required to validate our data.

\section{Conflict of Interest}

None declared.

\section{References}

1 Kim WH, Cho YJ, Park JY, Min PK, Kang JK, Park IS. Factors affecting insertion time and patient discomfort during colonoscopy. Gastrointest Endosc 2000;52(5):600-605

2 Rex DK, Imperiale TF, Latinovich DR, Bratcher LL. Impact of bowel preparation on efficiency and cost of colonoscopy. Am J Gastroenterol 2002;97(7):1696-1700

3 Davis GR, Santa Ana CA, Morawski SG, Fordtran JS. Development of a lavage solution associated with minimal water and electrolyte absorption or secretion. Gastroenterology 1980;78(5 Pt 1):991-995

4 Beck DE, Harford FJ, DiPalma JA, Brady CE III. Bowel cleansing with polyethylene glycol electrolyte lavage solution. South Med J 1985;78(12):1414-1416
5 Thomas G, Brozinsky S, Isenberg JI. Patient acceptance and effectiveness of a balanced lavage solution (Golytely) versus the standard preparation for colonoscopy. Gastroenterology 1982;82(3):435-437

6 DiPiro JT, Michael KA, Clark BA, et al. Absorption of polyethylene glycol after administration of a PEG-electrolyte lavage solution. Clin Pharm 1986;5(2):153-155

7 Di Palma JA, Rodriguez R, McGowan J, Cleveland Mv. A randomized clinical study evaluating the safety and efficacy of a new, reduced-volume, oral sulfate colon-cleansing preparation for colonoscopy. Am J Gastroenterol 2009;104(9):2275-2284

8 Patel V, Nicar M, Emmett M, et al. Intestinal and renal effects of low-volume phosphate and sulfate cathartic solutions designed for cleansing the colon: pathophysiological studies in five normal subjects. Am J Gastroenterol 2009;104(4):953-965

9 Pelham RW, Russell RG, Padgett EL, Reno FE, Cleveland Mv. Safety of oral sulfates in rats and dogs contrasted with phosphate-induced nephropathy in rats. Int J Toxicol 2009;28(2):99-112

10 Lai EJ, Calderwood AH, Doros G, Fix OK, Jacobson BC. The Boston Bowel Preparation Scale: a valid and reliable instrument for colonoscopy-oriented research. Gastrointest Endosc 2009;69(3 Pt 2):620-625

11 Calderwood AH, Jacobson BC. Comprehensive validation of the Boston Bowel Preparation Scale. Gastrointest Endosc 2010;72(4):686-692

12 Gao Y, Lin JS, Zhang HD, Lin MX, Cheng CS, Wu SZ. Pilot validation of the Boston Bowel Preparation Scale in China. Dig Endosc 2013;25(2):167-173

13 Calderwood AH, Schroy PC III, Lieberman DA, Logan JR, Zurfluh M, Jacobson BC. Boston Bowel Preparation Scale scores provide a standardized definition of adequate for describing bowel cleanliness. Gastrointest Endosc 2014;80(2):269-276

14 Sulz MC, Kröger A, Prakash M, Manser CN, Heinrich H, Misselwitz B. Meta-analysis of the effect of bowel preparation on adenoma detection: early adenomas affected stronger than advanced adenomas. PLoS One 2016;11(6):e0154149

15 Rex DK, Di Palma JA, Rodriguez R, McGowan J, Cleveland M. A randomized clinical study comparing reduced-volume oral sulfate solution with standard 4-liter sulfate-free electrolyte lavage solution as preparation for colonoscopy. Gastrointest Endosc 2010;72(2):328-336

16 Rex DK, DiPalma JA, McGowan J, Cleveland Mv. A comparison of oral sulfate solution with sodium picosulfate: magnesium citrate in split doses as bowel preparation for colonoscopy. Gastrointest Endosc 2014;80(6):1113-1123

17 Joshi V, Jain M, Srinivas M, et al. Bowel cleansing agents in clinical practice: a cross-sectional study on safety, efficacy, and predictor of good bowel preparation. J Dig Endosc. 2019;10(1):39 